\title{
Role of Central Amygdala Neuronal Ensembles in Incubation of Nicotine Craving
}

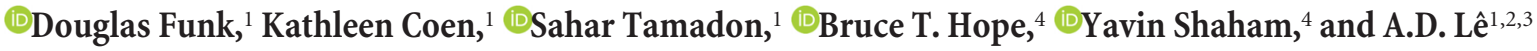 \\ ${ }^{1}$ Neurobiology of Alcohol Laboratory, Campbell Family Mental Health Research Institute, Centre for Addiction and Mental Health, Toronto, Canada M5S \\ 2S1, ${ }^{2}$ Departments of Pharmacology and Toxicology and ${ }^{3}$ Department of Psychiatry, University of Toronto, Toronto, Canada M5S 1A8, and ${ }^{4}$ Behavioral \\ Neuroscience Branch, Intramural Research Program, National Institute on Drug Abuse-National Institutes of Health, Baltimore, Maryland 21224
}

The craving response to smoking-associated cues in humans or to intravenous nicotine-associated cues in adult rats progressively increases or incubates after withdrawal. Here, we further characterized incubation of nicotine craving in the rat model by determining whether this incubation is observed after adolescent-onset nicotine self-administration. We also used the neuronal activity marker Fos and the Daun02 chemogenetic inactivation procedure to identify cue-activated neuronal ensembles that mediate incubation of nicotine craving. We trained adolescent and adult male rats to self-administer nicotine ( $2 \mathrm{~h} / \mathrm{d}$ for $12 \mathrm{~d}$ ) and assessed cue-induced nicotine seeking in extinction tests $(1 \mathrm{~h})$ after 1, 7, 14, or 28 withdrawal days. In both adult and adolescent rats, nicotine seeking in the relapse tests followed an inverted U-shaped curve, with maximal responding on withdrawal day 14 . Independent of the withdrawal day, nicotine seeking in the relapse tests was higher in adult than in adolescent rats. Analysis of Fos expression in different brain areas of adolescent and adult rats on withdrawal days 1 and 14 showed time-dependent increases in the number of Fos-positive neurons in central and basolateral amygdala, orbitofrontal cortex, ventral and dorsal medial prefrontal cortex, and nucleus accumbens core and shell. In adult Fos-lacZ transgenic rats, selective inactivation of nicotine-cue-activated Fos neurons in central amygdala, but not orbitofrontal cortex, decreased "incubated" nicotine seeking on withdrawal day 14 . Our results demonstrate that incubation of nicotine craving occurs after adolescent-onset nicotine self-administration and that neuronal ensembles in central amygdala play a critical role in this incubation.

Key words: central amygdala; Daun02; Fos; incubation of craving; nicotine; orbitofrontal cortex

\section{Significance Statement}

The craving response to smoking-associated cues in humans or to intravenous nicotine-associated cues in adult rats progressively increases or incubates after withdrawal. It is currently unknown whether incubation of craving also occurs after adolescent-onset nicotine self-administration. The brain areas that mediate such incubation are also unknown. Here, we used a rat model of incubation of drug craving, the neuronal activity marker Fos, and the Daun02 chemogenetic inactivation method to demonstrate that incubation of nicotine craving is also observed after adolescent-onset nicotine self-administration and that neuronal ensembles in the central nucleus of the amygdala play a critical role in this incubation in adult rats.

\section{Introduction}

Results from two studies showed that the response to smokingassociated cues in humans and to nicotine-associated cues in rats progressively increases or incubates after withdrawal (Abdolahi

\footnotetext{
Received May 6, 2016; revised June 14, 2016; accepted June 19, 2016.

Author contributions: D.F., B.T.H., Y.S., and A.D.L. designed research; D.F., K.C., and S.T. performed research; B.T.H. contributed unpublished reagents/analytic tools; D.F., K.C., and S.T. analyzed data;D.F., Y.S., and A.D.L. wrote the paper.

This work was supported by the National Institute on Drug Abuse-National Institutes of Health (Grant R21DA034394 to A.D.L. and Intramural Research Program grant to Y.S. and B.T.H.).

The authors declare no competing financial interests.

Correspondence should be addressed to Douglas Funk, Neurobiology of Alcohol Laboratory, Campbell Family Mental Health Research Institute, Centre for Addiction and Mental Health, 33 Russell Street, Toronto, Ontario, Canada M5S2S1. E-mail: Douglas.Funk@camh.ca.

DOI:10.1523/JNEUROSCI.1505-16.2016

Copyright $\odot 2016$ the authors $\quad 0270-6474 / 16 / 368612-12 \$ 15.00 / 0$
}

et al., 2010; Bedi et al., 2011). In the human study, Bedi et al. (2011) showed that nicotine-cue-induced subjective craving is higher after 35 withdrawal days than after 7 or $14 \mathrm{~d}$. In the rat study, Abdolahi et al. (2010) showed that, after nicotine selfadministration, extinction responding and subsequent cueinduced reinstatement after extinction are higher after 7 withdrawal days than after $1 \mathrm{~d}$. The results of Abdolahi et al. (2010) extend previous rat studies on "incubation of drug craving” after withdrawal from cocaine (Neisewander et al., 2000; Grimm et al., 2001), heroin (Shalev et al., 2001), methamphetamine (Shepard et al., 2004), or alcohol (Bienkowski et al., 2004). There is also evidence for incubation of cocaine or heroin craving after adolescent-onset drug self-administration (Li and Frantz, 2009; Doherty and Frantz, 2012), but it is unknown whether incubation of nicotine craving would occur after adolescent- 
onset nicotine self-administration, the developmental phase in which most nicotine addicts initiate smoking (Eissenberg and Balster, 2000). In addition, the time course and mechanisms of incubation of nicotine craving are unknown (Pickens et al., 2011; Wolf, 2016).

We addressed these questions in adolescent and adult rats that initiated nicotine self-administration on postnatal days (PD) 33PD35 and PD73-PD75, respectively. During self-administration training, nicotine infusions were paired with a discrete tone-light cue. We then tested groups of rats for "incubation of nicotine craving" in extinction tests performed on withdrawal days 1, 7, 14, and 28. During testing, lever presses led to contingent presentations of the cue previously paired with nicotine. This extinction-based procedure has been used in mechanistic studies of incubation of heroin (Airavaara et al., 2011), methamphetamine (Li et al., 2015b), and cocaine (Ben-Shahar et al., 2013; Lee et al., 2013; Loweth et al., 2014) craving.

In Experiment 1, we determined age differences in incubation of nicotine craving. Based on our previous study showing that extinction responding over days is lower after adolescentonset nicotine self-administration than after adult-onset selfadministration (Shram et al., 2008b), we predicted weaker incubation of nicotine craving in adolescent rats. We also used the activity marker Fos (Morgan and Curran, 1991) to identify brain regions showing stronger activation during the late withdrawal (day 14) versus early withdrawal (day 1) extinction tests. We chose withdrawal day 14 because maximal "incubated" nicotine seeking in the extinction tests was observed on this day. We studied the role of medial prefrontal cortex (mPFC, ventral and dorsal regions), orbitofrontal cortex (OFC, lateral region), nucleus accumbens (NAc, core and shell), and central and basolateral amygdalar nuclei (CeA and BLA, respectively) based on previous studies on the role of these regions in incubation of drug craving for heroin, cocaine, and methamphetamine (Pickens et al., 2011; Marchant et al., 2013; Wolf, 2016).

We found that time-dependent increases in nicotine seeking after withdrawal were associated with time-dependent increases in Fos expression in OFC and CeA. Therefore, in Experiments $2-3$, we determined the causal role of activated Fos-positive neurons in these brain regions in incubated nicotine seeking on withdrawal day 14. For this purpose, we used the Daun02 inactivation procedure that was developed to demonstrate a causal role of putative neuronal ensembles in learned behaviors (Koya et al., 2009 b). In this procedure, selective inactivation of behaviorally relevant activated neurons is performed by injecting the prodrug Daun02 into specific brain areas of Fos-lacZ transgenic rats (Kasof et al., 1996) that express $\beta$-galactosidase ( $\beta$-gal, the protein product of the lac $Z$ gene) in neurons that were strongly activated during behavior (Cruz et al., 2013). Previous studies using this procedure demonstrated causal roles of activated neuronal ensembles in different brain areas in context-induced reinstatement of cocaine and heroin seeking (Bossert et al., 2011; Cruz et al., 2014), incubation of heroin craving (Fanous et al., 2012), and cue-induced alcohol seeking (Pfarr et al., 2015).

\section{Materials and Methods}

\section{Subjects and apparatus}

We used a total of 188 male hemizygous Fos-lac $Z$ transgenic rats (Kasof et al., 1996) that we bred with Sprague Dawley females (Charles River Laboratories) in our animal facility. At PD20, we weaned the pups and kept them two per cage until we performed the intravenous catheter surgery (PD28-PD30 and PD68-PD70 for adolescents and adults, respectively). We assigned littermates to different groups to avoid a litter effect. We maintained the rats on a $12 \mathrm{~h} / 12 \mathrm{~h}$ light/dark cycle (lights on at 7:00 P.M.) with ad libitum access to food and water. We performed all experiments in accordance with the National Institutes of Health's Guide for the Care and Use of Laboratory Animals (8th edition) and received approval for the experimental protocols from the Animal Care and Use Committee of the Centre for Addiction and Mental Health (CAMH). At the time of weaning, we genotyped the rats at $\mathrm{CAMH}$ using established procedures. We excluded 11 adolescent and 20 adult rats from the study due to catheter failure, health issues, or cannula misplacement.

For nicotine self-administration, we used standard Med Associates self-administration chambers equipped with active and inactive levers, a house light, a cue light above the active lever, and a speaker. The house light was illuminated during the nicotine self-administration sessions. A compound visual (cue light, $30 \mathrm{~s}$ ) and auditory $(2900 \mathrm{~Hz}, 1 \mathrm{~s}$ ) cue was paired with nicotine infusions. We recorded inactive lever presses, but these presses had no programmed consequences. For sucrose pellet selfadministration, we used another set of operant chambers that were only equipped with a single lever.

\section{Drugs}

We purchased Daun02 from ApexBio and dissolved it in 5\% dimethyl sulfoxide (DMSO), 6\% Tween 80, and 89\% $0.1 \mathrm{M} \mathrm{PBS.} \mathrm{We} \mathrm{injected}$ Daun02 intracranially at a dose of $2 \mu \mathrm{g} / 0.5 \mu \mathrm{l} / \mathrm{side}$, a dose based on previous studies (Koya et al., 2009a; Bossert et al., 2011). We purchased nicotine hydrogen tartrate from MP Biomedicals, dissolved it in sterile saline, and adjusted the solution to $\mathrm{pH} 7$. The rats self-administered nicotine at a dose of $0.03 \mathrm{mg} / \mathrm{kg} /$ infusion (infusion volume $0.1 \mathrm{ml} / \mathrm{kg}$ ), a dose based on our previous studies in adolescent and adult rats (Shaham et al., 1997; Shram et al., 2008a, b) and other studies using the nicotine self-administration procedure in adult rats (Shoaib et al., 1997; Adriani et al., 2003; Kenny and Markou, 2006).

\section{Surgical procedures}

\section{Intravenous catheterization}

We used aseptic procedures throughout the surgery. We anesthetized the adolescent and adult rats with an isoflurane/oxygen mixture and implanted them with an intravenous catheter into the right jugular vein externalized above the scapulae. The length of the catheter below the incision of the vein was $25 \mathrm{~mm}$ for adolescent rats and $30 \mathrm{~mm}$ for adult rats. Before surgery, we injected the rats with the antibiotic penicillin $G$ (Derapen, 30,000 U, i.m.), the analgesic ketoprofen ( $5 \mathrm{mg} / \mathrm{kg}$, s.c.), and the local anesthetic bupivacaine $(0.125 \%, 0.1 \mathrm{ml}$, s.c., at incision sites). We gave the rats 1 week to recover from surgery and, during this time period and during the self-administration phase, we flushed the catheters daily with heparin $(0.1 \mathrm{ml}$ of $50 \mathrm{U} / \mathrm{ml})$. To verify catheter patency, we injected the rats intravenously with sodium thiopental $(0.2 \mathrm{ml}$ of 20 $\mathrm{mg} / \mathrm{ml}$ solution) after the last self-administration session.

\section{Intracranial cannula implantation}

We implanted adult Fos-lac $Z$ rats with bilateral intracranial guide cannulas (22 gauge; Plastics One) $1 \mathrm{~mm}$ above the OFC or CeA; we performed this surgery $5 \mathrm{~d}$ after the intravenous catheter surgery. We secured the cannulas to the skull with dental cement and jeweler's screws. We used the following coordinates [in millimeters from bregma, flat skull, based on the atlas of Paxinos and Watson (2005): OFC: anteroposterior +3.2 , mediolateral \pm 3.3 , dorsoventral -4.1 (10 degree angle); CeA: anteroposterior: -2.5 , mediolateral \pm 4.2 , dorsoventral -7.1$]$. These coordinates are based on previous studies on the role of OFC and CeA in incubation of drug craving (Lu et al., 2005; Lu et al., 2007; Fanous et al., 2012; Li et al., 2015a). At the end of Experiments 2-3, we verified cannula placements while photographing the brain sections after the $\beta$-gal immunohistochemistry assay.

\section{Intracranial injections of Daun02}

We injected Daun02 into the OFC or CeA at a dose of $2 \mu \mathrm{g} / 0.5 \mu \mathrm{l} / \mathrm{side}$. We gave the intracranial injections using $10 \mu$ l Hamilton syringes that were attached to 28 -gauge injectors with PE-20 tubing. The injectors were extended $1 \mathrm{~mm}$ below the tips of the guide cannulas. We injected 
Daun02 or its vehicle (5\% DMSO, 6\% Tween 80, and 89\% 0.1 м PBS) over $1 \mathrm{~min}$ and kept the injectors in place for $1 \mathrm{~min}$.

\section{Behavioral procedures}

The behavioral experiments included four phases: sucrose self-administration ( $2 \mathrm{~d})$, nicotine self-administration (12 d), withdrawal period $(1,7,14$, or $28 \mathrm{~d}$ ), and extinction tests (a single session at the different withdrawal days).

\section{Sucrose and nicotine self-administration training}

Sucrose. Before the intravenous catheter surgery, we trained the rats to lever press for $45 \mathrm{mg}$ sucrose pellets (BioServ, F06623) in a $7.5 \mathrm{~h}$ session and a $16 \mathrm{~h}$ session. During these sessions, lever presses were reinforced under a fixed ratio 1 (FR1) reinforcement schedule with no timeout period; no cues were associated with pellet delivery. We performed the sucrose self-administration training to facilitate the acquisition of nicotine self-administration. The mean \pm SEM of sucrose pellets earned on these days for adolescent and adult rats were as follows: day $1,47.1 \pm 5.9$ and $256.6 \pm 10.9$; day $2,88.6 \pm 7.4$ and $362.3 \pm 12.8$, respectively.

Nicotine. We trained adolescents and adult rats to self-administer nicotine $(0.03 \mathrm{mg} / \mathrm{kg} /$ infusion $)$ for $122 \mathrm{~h}$ daily sessions using procedures used previously in our studies (Lê et al., 2006; Shram et al., 2008a, b). At the beginning of each session, the house light was turned on and the active and inactive levers were extended. During the session, active lever presses were reinforced under an FR1 30 s timeout reinforcement schedule and nicotine infusions were paired with the compound tone-light cue.

\section{Withdrawal period}

During this period, we housed the rats in the animal facility for their assigned withdrawal period and handled them two to three times per week. In Experiment 1, we matched the groups of adolescent or adult rats assigned to the different withdrawal days for their nicotine intake during self-administration training. In Experiments 2-3, we matched the groups of adult rats assigned to vehicle or Daun02 conditions for their nicotine intake during self-administration training.

\section{Extinction tests}

The test sessions began with the extension of the active and inactive levers and the illumination of the house light, which remained on for the duration of the session $(1 \mathrm{~h})$. Active lever presses during testing (the operational measure of cue-induced drug seeking in incubation of craving studies (Lu et al., 2004b; Pickens et al., 2011; Venniro et al., 2016) resulted in contingent presentations of the tone-light cue previously paired with nicotine infusions but not nicotine.

\section{Immunohistochemistry}

We anesthetized the rats with sodium pentobarbital $(100 \mathrm{mg} / \mathrm{kg})$ and perfused them transcardially with $100 \mathrm{ml}$ of PBS, $\mathrm{pH} 7.4$, followed by 300 $\mathrm{ml}$ of cold $4 \%$ paraformaldehyde in phosphate buffer, $\mathrm{pH}$ 7.4. We then extracted the brains and stored them in buffered $4 \%$ paraformaldehyde for $1 \mathrm{~h}$. Next, we placed the brains in $30 \%$ sucrose in phosphate buffer for $48 \mathrm{~h}$, froze them in dry ice, and stored them at $-70^{\circ} \mathrm{C}$ until cryostat slicing. We cut $40 \mu \mathrm{m}$ brain slices on a cryostat, collected the slices in solution containing $0.1 \%$ Tween $20 / \mathrm{PBS}$, and stored them in a cryoprotectant solution (30\% glycerol/ $30 \%$ ethylene glycol in phosphate buffer) at $-20^{\circ} \mathrm{C}$. We collected brain sections from the following brain areas (expressed in millimeters from bregma): dorsal and ventral $\mathrm{mPFC}$ and OFC ( +4.2 to 3.2$)$, NAc core and shell $(+2.2$ to 1.2$)$, and CeA and BLA $(-2.12$ to -2.9$)$.

\section{Fos immunohistochemistry with DAB labeling}

We made the solutions in TBS-T (Tris-buffered saline with $0.2 \%$ Triton $\mathrm{X}-100$ ). We rinsed the sections 3 times, incubated them in $0.35 \% \mathrm{H}_{2} \mathrm{O}_{2}$ for $30 \mathrm{~min}$ to reduce endogenous peroxidase, rinsed them again 3 times, and blocked them in 3\% normal goat serum (NGS) for $1 \mathrm{~h}$. Next, we incubated the sections with rabbit anti-Fos (1:4000, SC52, lot \#C2113; Santa Cruz Biotechnology) with 3\% NGS at room temperature overnight on a shaker, rinsed the sections 3 times, and incubated them with biotin- ylated anti-rabbit secondary antibody for $2 \mathrm{~h}$ (1:200, BA1000, lot \#Y0515; Vector Laboratories) with $1 \%$ NGS. Next, we treated the sections with avidin/biotin horseradish peroxidase (Vectastain Elite; Vector Laboratories), followed by three rinses, and then exposed the sections to $0.5 \%$ diaminobenzidine solution (with $0.035 \% \mathrm{H}_{2} \mathrm{O}_{2}$ and $0.032 \% \mathrm{NiCl}_{2}, \mathrm{pH}$ 7.8 ) until the desired staining intensity was achieved ( $\sim 4 \mathrm{~min})$. We terminated the reaction with three rinses, mounted the sections on Superfrost Plus glass slides, dried the sections overnight, dehydrated them, and coverslipped them with DPX (Sigma-Aldrich, 06522).

\section{Immunofluorescence double-labeling histochemistry for Fos/ $\beta$-gal or Fos/NeuN}

We rinsed the sections 3 times with TBS and incubated them with rabbit anti-Fos (1:500, sc52, lot \#C2113; Santa Cruz Biotechnology) and mouse anti- $\beta$-gal (1:1000, sc65670, lot \#A2611; Santa Cruz Biotechnology) or mouse anti-NeuN (1:4000, MAB377, lot $\# 2159655$; Millipore) at $4^{\circ} \mathrm{C}$ for $48 \mathrm{~h}$. Next, we rinsed the sections three times and incubated them with donkey anti-rabbit Alexa Fluor 488 (1:200, A21206, lot \#1480470; Invitrogen) and goat anti-mouse Alexa Fluor 568 (1:200, A11004; lot \#1419715; Invitrogen), followed by 3 rinses. We then mounted the sections on slides, dried them overnight, and coverslipped them with Vectashield Hardset (Vector Laboratories, H-1400).

\section{$\beta$-Galactosidase ( $\beta$-gal) assay}

We rinsed the brain sections 3 times for $15 \mathrm{~min}$ in phosphate buffer, $\mathrm{pH}$ 7.4 , and then incubated them in X-galactosidase (X-gal) reaction solution $\left(2 \mathrm{~mm} \mathrm{MgCl}_{2}, 5 \mathrm{~mm}\right.$ EGTA, $5 \mathrm{~mm} \mathrm{~K} 3\left[\mathrm{Fe}(\mathrm{CN})_{6}\right], 5 \mathrm{~mm} \mathrm{~K} 4\left[\mathrm{Fe}(\mathrm{CN})_{6}\right]$, $2.45 \mathrm{~mm} \mathrm{X}-\mathrm{Gal}$ in phosphate buffer, $\mathrm{pH}$ 7.6) for $4.5 \mathrm{~h}$ at room temperature in the dark. We then rinsed the sections three times in phosphate buffer, mounted them on slides, air dried them overnight, and coverslipped them with DPX.

\section{Image analysis and neuronal quantification}

Fos-DAB. We photographed the brain slices with a light microscope under $100 \times$ magnification (field size $0.193 \mathrm{~mm}^{2}$ ). We then counted the number of Fos-positive neurons in the images (six to eight images per brain area per rat) using particle analysis software (ImageJ). We calculated the mean counts per brain area per square millimeter across images within each rat and used these mean counts in the statistical analyses. Fos/NeuN and Fos/ $\beta$-gal double-labeling. We photographed the slices stained for Fos, NeuN, $\beta$-gal, Fos/NeuN, and Fos/ $\beta$-gal using a fluorescence microscope at $400 \times$ magnification (field size $0.074 \mathrm{~mm}^{2}$ ) and counted 4-6 images per brain area per rat.

$\beta$-gal. We photographed the brain slices of OFC and CeA using a light microscope under $100 \times$ magnification. We counted four to six images per brain area per rat using ImageJ.

\section{Specific experiments}

Experiment 1: Incubation of nicotine craving and Fos expression after nicotine self-administration during adolescence and adulthood

We used adolescent ( $n=43,4$ groups, $n=7-13$ per group) and adult ( $n=43,4$ groups, $n=8-13$ ) male Fos-lac $Z$ rats that we trained to self-administer nicotine for $12 \mathrm{~d}$ for $2 \mathrm{~h} / \mathrm{d}$ and tested them for extinction responding $(1 \mathrm{~h})$ after $1,7,14$, and 28 withdrawal days. We used a fully factorial experimental design that included the between-subjects factor of age (adolescents, adults) and withdrawal day $(1,7,14,28)$. Immediately after the $1 \mathrm{~h}$ extinction tests, we deeply anesthetized the rats, perfused them, and dissected their brains for subsequent Fos protein immunohistochemistry and fluorescence immunohistochemistry for Fos $+\beta$-gal and Fos + NeuN double labeling.

We also trained other groups of adolescent Fos-lac $Z$ rats (2 groups, $n=$ 5-6 per group) and adult Fos-lac $Z$ rats ( 2 groups, $n=5$ per group) to self-administer nicotine for $12 \mathrm{~d}$. We did not expose these rats to the extinction tests and, on withdrawal days 1 or 14, we deeply anesthetized and then perfused them and dissected their brains for a subsequent Fos protein immunohistochemistry assay. We ran these groups to determine whether there were age differences in basal Fos expression, which can be a potential confound in interpreting the Fos data of the adolescent and 
adult rats exposed to the extinction tests. Finally, based on the behavioral data of maximal nicotine seeking on withdrawal day 14, we only performed the Fos immunhistochemistry assays on rats tested on withdrawal days 1 and 14 .

Experiment 2: Effects of selective inhibition of activated OFC neurons with Daun02 on incubated nicotine seeking

We implanted adult male Fos-lac $Z$ rats ( $n=29, n=6-8$ per group) with intravenous catheters and bilateral cannulas aimed at the OFC and trained them to self-administer nicotine for $12 \mathrm{~d}(2 \mathrm{~h} / \mathrm{d})$. The experimental procedure with Daun02 is based on our previous study on the role of OFC in incubation of heroin craving (Fanous et al., 2012) and includes two phases (the induction phase and the test phase) and four experimental groups in a fully factorial experimental design that includes the between-subjects factors of Fos induction context (nicotine selfadministration context, novel context) and Daun02 dose (vehicle, $2 \mu \mathrm{g}$ ). On induction day (withdrawal day 11), we briefly exposed the rats to the nicotine self-administration context and cues associated with nicotine injections in a 15 min extinction session or to a novel context (control condition) to induce Fos in OFC. Next, 75 min after exposure to these conditions, a time of strong Fos (and $\beta$-gal) expression (Koya et al., 2009b), we injected the rats with Daun02 (to inactivate the activated neurons) or vehicle. On test day, 3 d later (withdrawal day 14), we tested all rats in a 90 min extinction session. Immediately after the extinction tests, we perfused the rats and extracted their brains for a subsequent $\mathrm{X}$-gal histochemistry assay of $\beta$-gal expression in the OFC and verification of cannula placements. We also measured $\beta$-gal expression in the insular cortex adjacent to the OFC to determine the anatomical specificity of the Daun02 injections. The novel context consisted of visually distinct (opaque vs clear) cages with a different type of bedding material (extruded newsprint vs corncob) than either the rats' home cages or the cages used to transport them to the testing rooms.

Experiment 3: Effects of selective inhibition of activated CeA neurons with Daun02 on incubated nicotine seeking

The procedures of Experiment 3 were identical to those of Experiment 2 with the exception that we injected Daun02 or vehicle into the CeA. We used 4 groups of rats (total $n=42$ and $n=9-12$ per group). We also measured $\beta$-gal expression in the BLA to determine the anatomical specificity of the Daun02 injections.

\section{Statistical analysis}

We analyzed the data using SPSS (version 21). In Experiment 1 extinction tests, we analyzed age and withdrawal day differences in nonreinforced active lever presses using analysis of covariance with the between-subjects factors of age (adolescents, adults) and withdrawal day $(1,7,14,28)$ and the covariate of inactive lever presses. For the Fos data in Experiment 1, we used the between-subjects factors of age and withdrawal day $(1,14)$; we performed this analysis separately for each brain region. In Experiments 2-3, we analyzed the effect of Daun02 on nonreinforced lever presses during the extinction tests on withdrawal day 14 using analysis of covariance with the between-subjects factors of induction context (nicotine self-administration chambers, novel context) and Daun02 dose $(0,2 \mu \mathrm{g})$ and the covariate of inactive lever presses. Because of large individual variability and skewed distributions in some of the vehicle groups, we square-root transformed the raw values of the active and inactive lever data in Experiments $2-3$. We also analyzed the $\beta$-gal expression data using the between-subjects factors of induction context and Daun02 dose. We followed up on significant main or interaction effects $(p<0.05)$ with Fisher's PLSD post hoc tests.

\section{Results}

Incubation of nicotine craving and Fos expression after nicotine self-administration during adolescence versus adulthood

In Experiment 1, we determined whether there are age differences in the time-dependent increases in nicotine seeking after withdrawal (incubation of nicotine craving) and whether these timedependent differences are associated with time-dependent increases in neuronal activation in different brain areas as assessed by the neuronal activity marker Fos. At the behavioral level, we determined four withdrawal time points (days 1, 7, 14, and 28). For Fos, we compared Fos expression in adults and adolescent rats after 1 and $14 \mathrm{~d}$, the time period of maximal incubated nicotine seeking in both age groups. We first describe the nicotine self-administration data and then the incubation of craving and Fos expression data. The timeline of Experiment 1 is depicted in Figure $1 A$.

\section{Nicotine self-administration training}

Figure $1 B$ shows the mean \pm SEM number of nicotine infusions and presses on the active lever and on the inactive lever in adolescent $(n=43)$ and adult $(n=43)$ rats during the training phase. The rats demonstrated reliable nicotine selfadministration as indicated by the stable nicotine intake over time and reliable active versus inactive lever discrimination in both adolescents and adults $(p<0.01$ for a main effect of lever). We did not observe age differences in nicotine selfadministration, a finding that replicates our previous study (Shram et al., 2008b), but, in the current study, responding on the inactive lever was higher in adolescent but not adult rats. The initial higher responding on the active lever on the first one or two training days is likely due to a carry-over effect of the sucrose self-administration training that was performed in different self-administration chambers.

\section{Incubation of nicotine craving}

Figure $1 C$ shows the mean \pm SEM number of presses on the previously active lever and the inactive lever made by adolescent and adult rats during the extinction tests at the different withdrawal days. In both adolescent and adult rats, extinction responding followed a time-dependent inverted U-shaped curve with maximal responding on withdrawal day 14 . In addition, independent of the withdrawal day, active lever presses in the extinction tests were higher in adult rats than in adolescent rats. The ANCOVA (inactive lever presses as a covariate) showed main effects of withdrawal day $\left(F_{(3,77)}=5.2, p<0.01\right)$ and age $\left(F_{(1,77)}=8.4, p<0.01\right)$, but no interaction between the two factors $(p>0.1)$. There was no effect of withdrawal day or age on inactive lever presses, which was significantly lower than active lever presses at all time points $(p<0.01)$. Post hoc group differences for active lever presses are indicated in Figure 1.

\section{Fos expression}

Figure 2 shows the mean \pm SEM number of Fos-IR neurons in mPFC (ventral and dorsal), OFC, NAc (core and shell), and amygdala (central and basolateral) in adolescent and adult rats exposed to the extinction tests after 1 or 14 withdrawal days. Overall, across the different brain regions and independent of age, Fos expression was higher after 14 withdrawal days than after $1 \mathrm{~d}$. The results of the 2 (withdrawal day) $\times 2$ (age) factorial ANOVA showed significant effects of withdrawal day for dorsal and ventral mPFC $\left(F_{(1,43)}=10.6\right.$ and 5.3, $\left.p<0.05\right)$, OFC $\left(F_{(1,39)}\right.$ $=22.6, p<0.01)$, NAc core and shell $\left(F_{(1,42)}=27.0\right.$ and 5.2, $p<$ $0.05)$, CeA $\left.F_{(1,44)}=16.4, p<0.01\right)$, and BLA $\left(F_{(1,42)}=7.4, p<\right.$ $0.05)$. The statistical analysis did not show an interaction between withdrawal day and age for any of the brain regions. For the dorsal mPFC, the analysis showed a main effect of age $\left.F_{(1,43)}=5.9, p<0.01\right)$ due to somewhat higher Fos expression in adult versus adolescent rats at both withdrawal days. Post 


\section{A Timeline}

\section{Age (PD)}

Adolescents: $25-27$

28-30

33-35

45-47

$51-53$

$58-60$

$72-74$

Adults: $65-67$

$68-70$

73-75

85-87

$91-93$

$99-101$

$110-112$

\begin{tabular}{|c|c|c|} 
Food training & Recovery & Nicotine training \\
\hline $2 \mathrm{~d}$ & $5 \mathrm{~d}$ & $12 \mathrm{~d} \times 2 \mathrm{~h} / \mathrm{d}$ \\
\multicolumn{2}{|c}{ Catheterization } &
\end{tabular}

$\uparrow \uparrow \uparrow$

$\begin{array}{ccc}\text { Day } 1 & \text { Day } 7 & \text { Day } 14 \\ \text { Incubation test day }\end{array}$

Day 28

\section{B Self-administration training}
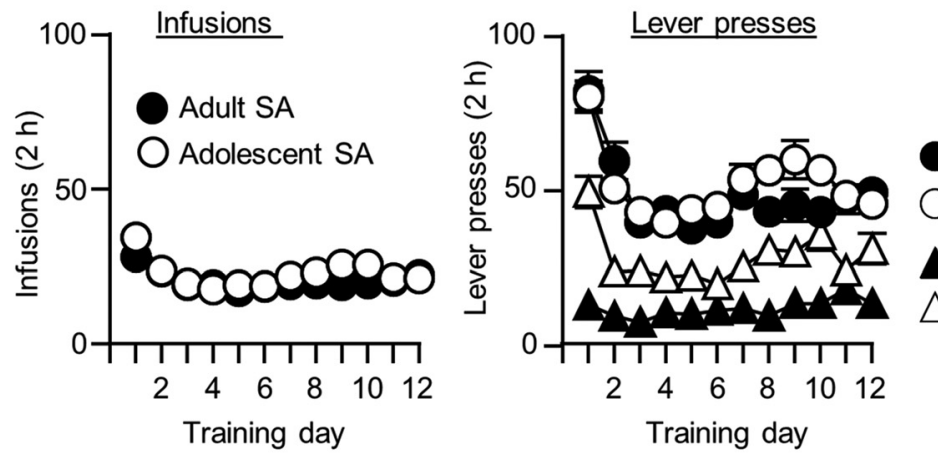

Adult: active lever

Adolescent: active lever

Adult: inactive lever

Adolescent: inactive lever
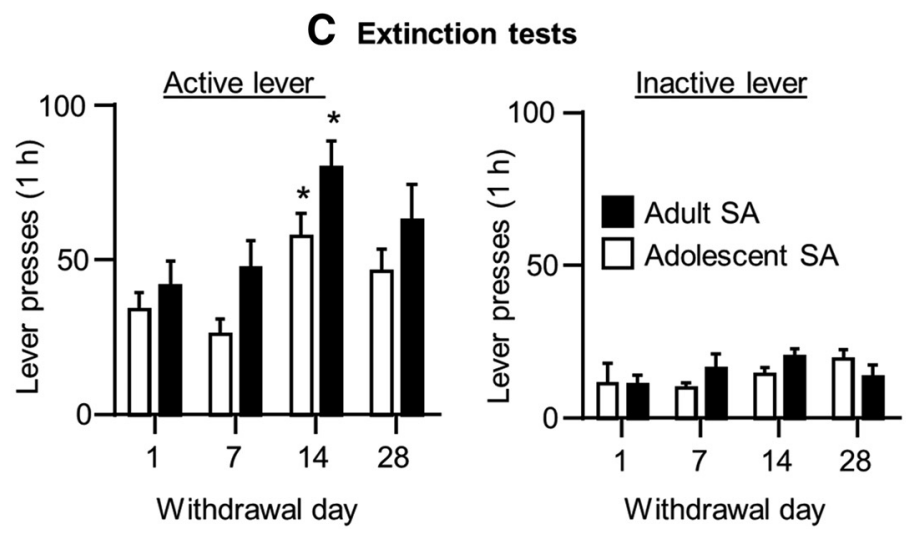

Figure 1. Incubation of nicotine craving in adolescent and adult rats. $\boldsymbol{A}$, Timeline of the experimental procedure. $\boldsymbol{B}$, Nicotine self-administration training in adolescents $(n=43)$ and adults $(n=$ 43) rats. Data are mean \pm SEM numbers of infusions and active and inactive lever presses during the 12 training days. $C$, Nicotine seeking in the extinction tests at different withdrawal days. Data are mean \pm SEM numbers of nonreinforced presses on the previously active lever and on the inactive lever. ${ }^{*}$ Different from day $1, p<0.05$ within each age group, $p<0.05 . n=7-13$ rats per group. SA, Self-administation.

hoc group differences within each withdrawal time point are shown in Figure 2.

Finally, a limitation of interpretation of the Fos data described in Figure 2 is that it is unknown whether the time-dependent changes in Fos expression reflect enhanced motivation to seek nicotine and/or enhanced responding to nicotine-associated cues after withdrawal or time-dependent increases in basal neuronal activity after withdrawal. To address this interpretation issue, we trained additional groups of adolescent and adult rats and determined Fos expression after 1 or 14 withdrawal days without performing the extinction tests. We found neither time-dependent changes nor age differences in basal Fos expression in the different brain areas (Table 1). We did not directly compare the no test and extinction test conditions because both the behavioral experiments and the Fos assays were performed at different time points and more than a year apart.
Double-labeling of Fos with NeuN and $\beta$-gal

We performed more qualitative analyses of double-labeling of Fos with the neuronal marker NeuN and $\beta$-gal in a subsample of adolescents and adult rats ( $n=4-6$ per age group) that were tested on withdrawal day 14 (Fig. 3). We restricted these analyses to the OFC and $\mathrm{CeA}$, the brain areas in which we determined the causal role of the Fos-positive neurons activated during the extinction tests in incubated nicotine seeking on withdrawal day 14. We determined Fos + NeuN double-labeling to obtain an estimate of the proportion of neurons strongly activated during testing, which we hypothesize form the neuronal ensemble that mediates incubation of nicotine craving. We determined Fos $+\beta$-gal double-labeling to verify that our Daun02 manipulation does indeed target the majority of the Fos neurons activated during the extinction tests.

The quantification of the Fos + NeuN double-labeled neurons in OFC and CeA, respectively, showed that $20 \pm 1.9 \%$ and 


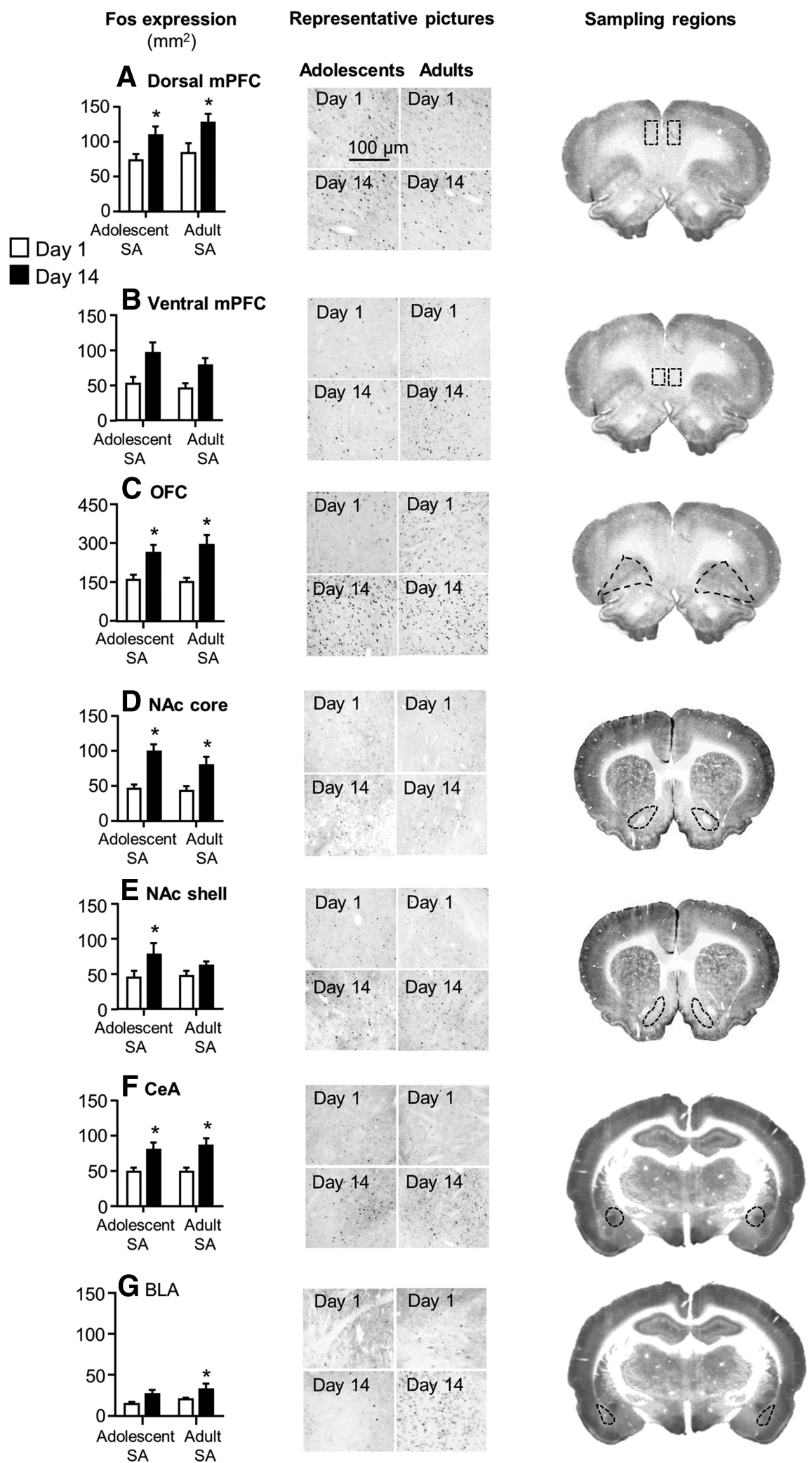

Figure 2. Incubation of nicotine craving in adolescent and adult rats is associated with increased neuronal activity in $\mathrm{mPFC}, \mathrm{OFC}, \mathrm{NAc}$, and amygdala. Data are mean \pm SEM numbers of Fos-IR neurons in dorsal and ventral mPFC $(\boldsymbol{A}, \boldsymbol{B}), 0 \mathrm{FC}$ $(\boldsymbol{C})$, NAc core and shell $(\boldsymbol{D}, \boldsymbol{E})$, and central and basolateral amygdala $(\boldsymbol{F}, \boldsymbol{G})$ of adolescent and adult rats exposed to the extinction tests on withdrawal days 1 or 14. Left, Mean \pm SEM Fos-labeled neurons. Center, Representative photomicrographs of Fos expression from the different groups (scale bar, $100 \mu \mathrm{m}$ ). Right, Sampling regions. *Different from day 1 within each age group, $p<0.05 . n=10-13$ per group. SA, Self-administation.
$24 \pm 3.1 \%$ and $10 \pm 1.2 \%$ and $9 \pm 0.8 \%$ of the NeuN neurons were Fos-positive in adolescent and adult rats, respectively. The quantification of the Fos $+\beta$-gal double-labeled neurons in OFC and CeA, respectively, showed that $77 \pm 5.3 \%$ and $78 \pm 2.9 \%$ and $78 \pm 4.5 \%$ and $75 \pm 9.7 \%$ of the $\beta$-gal neurons were Fos-positive in adolescent and adult rats, respectively. The observation of $<100 \%$ overlap between Fos and $\beta$-gal is in agreement with our previous studies (Bossert et al., 2011; Fanous et al., 2012) and likely reflects the different sensitivity of the different antibodies that we used in the doublelabel fluorescence immunohistochemistry assay.

\section{Selective inhibition of activated CeA but not OFC neurons with Daun02} decreased incubated nicotine seeking We used the Daun02 inactivation procedure to determine the causal role of putative OFC and CeA neuronal ensembles in incubated nicotine seeking. Figures 4 and 5 show the effect of prior exposure to Daun02 on withdrawal day 11 on the number of responses on the previously active lever and on the inactive lever during the extinction tests performed on withdrawal day 14 . These figures also show the effect of Daun02 on $\beta$-gal expression after the day 14 extinction test, as well as the nicotine self-administration data in Experiments $2-3$. In both experiments, there were no differences in extinction responding during the short 15 min extinction test on withdrawal day 11 before vehicle or Daun02 injections (OFC: vehicle group, $45.3 \pm 12.2$; Daun02 group, $52.6 \pm 9.6$; CeA: vehicle group, $54.3 \pm$ 10.3; Daun02 group, $46.2 \pm 9.2$ (values are mean \pm SEM of active lever presses per $15 \mathrm{~min}$ ).

\section{OFC}

Daun02 injections after short (15 min) exposure to the nicotine-associated context and cues in an extinction test performed on withdrawal day 11 had no effect on nicotine seeking on withdrawal day 14 (Fig. 4). The ANCOVA of number of responses on the active lever during the day 14 extinction tests, which included the between-subjects factors of induction context on day 11 (nicotine context, novel context) and Daun02 dose (0,2 $\mu \mathrm{g} / \mathrm{side})$ and inactive lever presses as a covariate, showed no main effects of the two factors or an interaction between them $(p>0.1)$. Daun02 injections had no effect on inactive lever presses during the day 14 extinction tests $(p>0.1)$. The statistical analysis 
Table 1. Mean \pm SEM Fos-labeled neurons (per square millimeter) of the 4 groups of rats ( $n=5-6$ each group) that were not exposed to the extinction tests after 1 or 14 withdrawal days

\begin{tabular}{|c|c|c|c|c|}
\hline \multirow[b]{2}{*}{ Brain area } & \multicolumn{2}{|c|}{ Adolescent self-administration } & \multicolumn{2}{|c|}{ Adult self-administration } \\
\hline & $1 d$ & $14 \mathrm{~d}$ & $1 d$ & $14 d$ \\
\hline dmPFC & $12.9 \pm 0.7$ & $15.9 \pm 2.7$ & $14.3 \pm 3.8$ & $15.9 \pm 1.6$ \\
\hline vmPFC & $59.8 \pm 9.6$ & $54.1 \pm 8.7$ & $58.3 \pm 11$ & $52.4 \pm 12.2$ \\
\hline OFC & $80.7 \pm 11.7$ & $81.6 \pm 11.5$ & $68 \pm 3.4$ & $62.8 \pm 4.6$ \\
\hline NAc core & $22.9 \pm 6.2$ & $20.7 \pm 3.8$ & $24 \pm 5.0$ & $25.2 \pm 5.0$ \\
\hline NAs shell & $16.1 \pm 1.7$ & $14.5 \pm 1.7$ & $12.1 \pm 1.6$ & $15.7 \pm 1.4$ \\
\hline CeA & $35.3 \pm 4.8$ & $39.1 \pm 10.5$ & $23.2 \pm 4.5$ & $33.6 \pm 9.5$ \\
\hline BLA & $14.1 \pm 1.0$ & $12.3 \pm 1.7$ & $15.2 \pm 1.6$ & $10.5 \pm 1.5$ \\
\hline
\end{tabular}

of $\beta$-gal expression in the OFC, which included the betweensubjects factors of induction context and Daun02 dose, showed a significant interaction between the two factors $\left(F_{(1,25)}=4.4, p<\right.$ $0.05)$; rats injected with Daun02 in the OFC after nicotine context exposure on induction day had lower $\beta$-gal levels than rats injected with vehicle or rats injected with Daun02 or vehicle after exposure to the novel context. Post hoc differences are shown in Figure 4. Finally, in rats injected with Daun02 or vehicle in the nicotine context on induction day, $\beta$-gal expression in the anterior insular cortex adjacent to the OFC did not differ between the two groups (vehicle, 258.1 \pm 29.3; Daun02, $257.9 \pm 47.8$; values are mean \pm SEM $\beta$-gal-labeled neurons per square millimeter). These data indicate that the Daun2 injections into the OFC were anatomically specific.

\section{CeA}

Daun02 injections after short (15 $\mathrm{min}$ ) exposure to nicotineassociated context and cues in an extinction test performed on withdrawal day 11 decreased nicotine seeking on withdrawal day 14 (Fig. 5). The Daun02 manipulation also decreased $\beta$-gal expression. The ANCOVA of number of responses on the active lever during the day 14 extinction tests, which included the between-subjects factors of induction context on day 11 and Daun02 dose and inactive lever presses as a covariate, showed a significant main effect of Daun02 dose $\left(F_{(1,37)}=6.3, p<0.05\right)$; the effects of induction context or the interaction between the two factors were not significant. However, because in the nicotine context condition, Daun02 injections decreased active lever presses by $\sim 50 \%$ (Fig. $5 C$ ), we performed post hoc tests within each induction context condition. These tests showed a significant difference between Daun02 and vehicle for the nicotine context condition $(p<0.05)$, but not the novel context condition $(p>0.1)$. Daun02 injections had no effect on inactive lever presses during the day 14 extinction tests $(p>0.1)$. The statistical analysis of $\beta$-gal expression showed an interaction between induction context and Daun02 dose $\left(F_{(1,37)}=4.6, p<0.05\right)$. Post hoc group differences are shown in Figure 5. Finally, in rats injected with Daun02 or vehicle in the nicotine context on induction day, $\beta$-gal expression in the BLA adjacent to the CeA did not differ between the two group (vehicle, $52.1 \pm 4.9$; Daun02, $48.4 \pm 2.5$; values are mean \pm SEM $\beta$-gal-labeled neurons per square millimeter), indicating that Daun2 injections into the CeA were anatomically specific.

\section{Discussion}

We used an extinction-based experimental procedure (Pickens et al., 2011; Wolf, 2016) to study time-dependent increases in nicotine seeking after withdrawal (incubation of nicotine craving) after adolescent- and adult-onset drug self-administration in rats. We report four main findings. First, in both age groups, incubation of
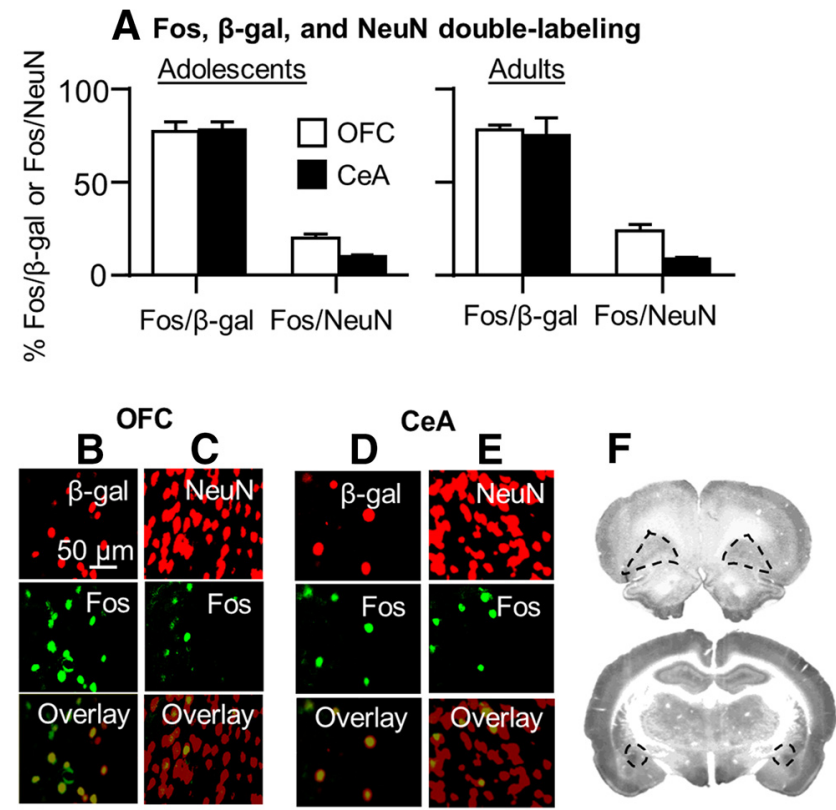

Figure 3. Double-labeling ofFos with $\beta$-gal and NeuN in the OFC and CeA.A, percentage of Fos + $\beta$-gal and Fos + NeuN double-labeled neurons in OFC and CeA in adolescent (left) and adult rats (right) perfused after extinction tests on withdrawal day 14. Pictures of double-labeling of adult Fos $+\beta$-gal and Fos + NeuN in the $\mathrm{OFC}(\boldsymbol{B}, \boldsymbol{C})$ and $C$ eA $(\boldsymbol{D}, \boldsymbol{E})$ of adult Fos-lacZ rats that underwent an extinction test on withdrawal day 14. Red, $\beta$-gal or NeuN (top); green, Fos (middle); yellow, Fos + $\beta$-gal and Fos + NeuN double-labeled neurons (bottom). Scale bar, $50 \mu \mathrm{m}$. F, Brain images indicating sampling regions for the OFC (top) and CeA (bottom).

nicotine craving followed an inverted U-shaped curve with maximal incubated responding on withdrawal day 14 . Second, independent of the withdrawal period, nicotine seeking in the extinction tests was higher in adult rats. Third, in both age groups, incubated nicotine seeking on withdrawal day 14 was associated with increased neuronal activity (assessed by Fos) in mPFC, NAc, OFC, and amygdala. Fourth, in adult rats, Daun02 inactivation of Fos-positive neurons in $\mathrm{CeA}$, but not OFC, decreased incubated nicotine seeking. Our study extends a previous report of Abdolahi et al. (2010) on incubation of nicotine craving after adult-onset nicotine self-administration, showing that this incubation also occurs after adolescent-onset nicotine self-administration, and demonstrates a causal role of CeA neuronal ensembles in incubation of nicotine craving.

\section{Nicotine self-administration and incubation of nicotine craving in adolescent and adult rats}

We studied incubation of nicotine craving after adolescent- and adult-onset nicotine self-administration because initiation of smoking most often occurs during adolescence (Clark et al., 1998; Eissenberg and Balster, 2000; Johnson, 2001). In addition, some evidence suggests that adolescent-onset smoking is associated with lower abstinence rates (Khuder et al., 1999). The biological mechanisms underlying addiction vulnerability in adolescent-onset smokers are unknown and human studies cannot differentiate between two hypotheses that are not mutually exclusive: (1) age-independent genetic vulnerability (i.e., vulnerable individuals initiate smoking when cigarettes are available independent of age) versus (2) age-dependent biological differences in nicotine reward (adolescents are more sensitive than adults to nicotine's rewarding effects) (Shram et al., 2008b).

Studies using the drug self-administration procedure in rats primarily assessed the second hypothesis and produced mixed results. Two studies reported higher nicotine self-administration in adoles- 


\section{A Timeline: Experiment 2}

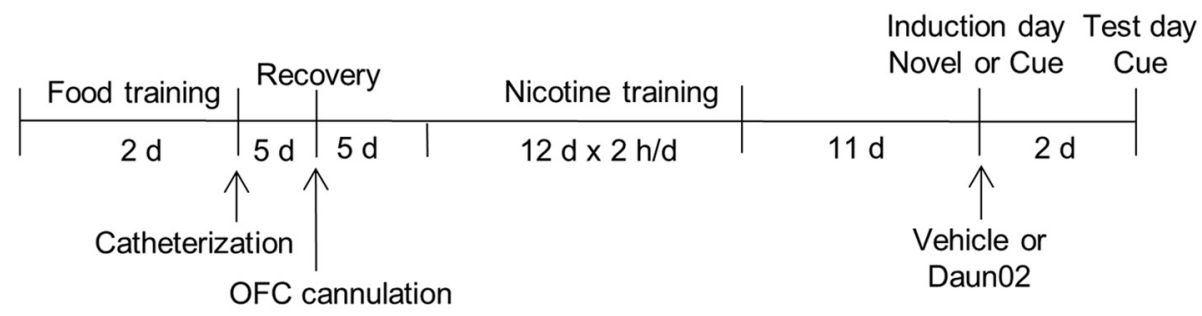

\section{B Nicotine self-administration}

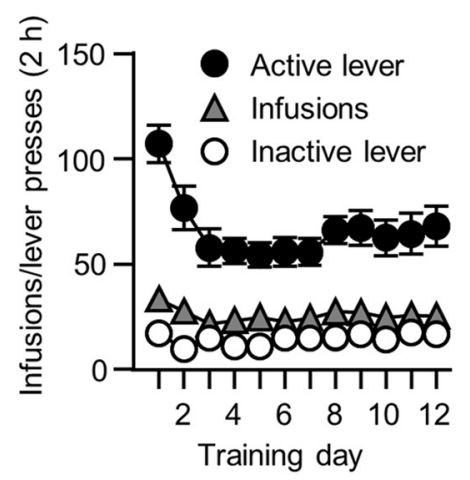

\section{E $\beta$-gal expression}

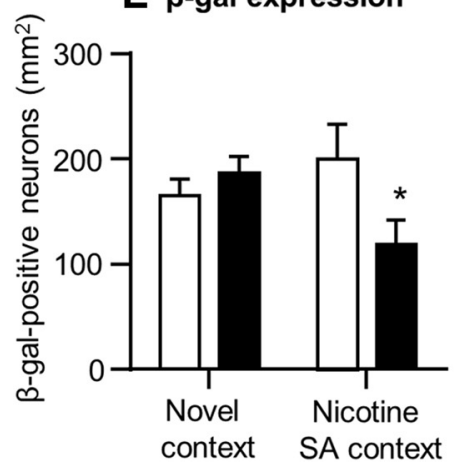

\section{Extinction test}
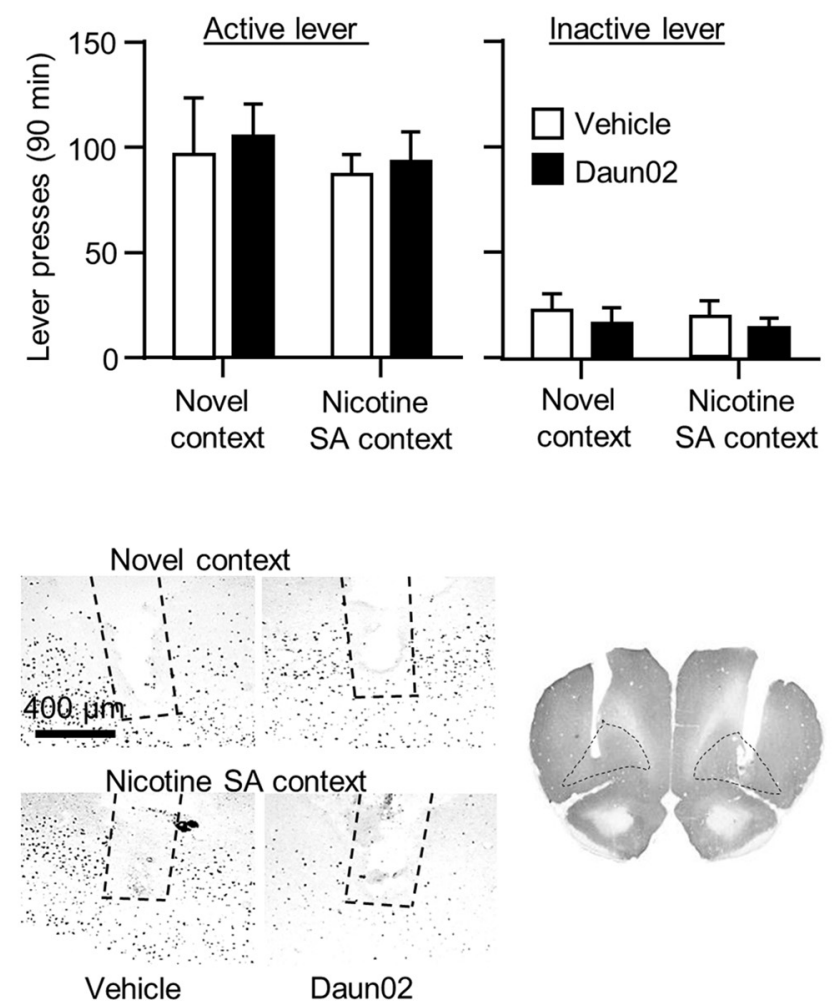

D Cannula placements

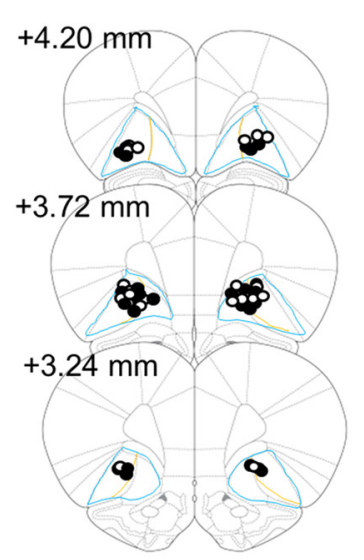

Figure 4. Daun02 injections into the OFC of adult Fos-lacZ rats had no effect on incubated nicotine seeking on withdrawal day 14 . $\boldsymbol{A}$, Timeline of the experimental procedure. $\boldsymbol{B}$, Nicotine self-administration. Data are mean \pm SEM of nicotine infusions and active and inactive lever presses of all rats (total $n=29$ ) during the 12 training days. $C$, Extinction responding. Data are mean \pm SEM of presses on the previously active lever and on the inactive lever during the extinction test after 14 withdrawal days. $\boldsymbol{D}$, Cannula placements. Numbers indicate millimeters from bregma. $\boldsymbol{E}, \beta$-gal expression. Left, Mean \pm SEM $\beta$-gal-positive neurons in the OFC in the four groups. Right, Representative photomicrographs of $\beta$-gal expression in the 0FC of rats in the different treatment groups. We injected the rats with Daun02 or vehicle 75 min after a short 15 min extinction session in the nicotine self-administration context or exposure to a novel context on withdrawal day $11 . n=6-8$ per group.

cent rats (Levin et al., 2003; Belluzzi et al., 2005). In contrast, we found no age differences in initiation of nicotine self-administration or nicotine priming-induced reinstatement of drug seeking; we also found that lever responding under a progressive ratio reinforcement schedule and resistance to extinction are lower in adolescent rats than in adult rats (Shram et al., 2008a, b). Our current results-no age differences in initiation and maintenance of nicotine selfadministration and lower nicotine seeking in the extinction testsare in agreement with results from our previous studies. To the degree that the rodent intravenous drug self-administration and the reinstatement/relapse procedures are relevant to human addiction (Brady, 1991; Epstein et al., 2006; Heilig et al., 2016), the results of our previous and present study do not support the popular hypothesis of greater biological vulnerability to nicotine addiction during adolescence. However, from the perspective of the generality of our findings to the human condition, two factors should be considered. The first is that the adolescent phase in rats is $\sim 30-40 \mathrm{~d}$, whereas this phase in humans lasts for several years (Spear, 2000; McCutcheon and Marinelli, 2009). The second is the different routes of nicotine administration in the rat studies (intravenous) versus the human condition (smoking) (Rose and Corrigall, 1997).

Our results of lower extinction responding and "lower" magnitude of incubation of nicotine craving are in agreement with results from previous studies showing less robust incubation of heroin (Doherty et al., 2013), cocaine (Li and Frantz, 2009), and sucrose (Counotte et al., 2014) craving in adolescent rats. In contrast, the time course of incubation of nicotine craving in our study is different from that observed in the Abdolahi et al. (2010) study (higher nicotine seeking on day 7 versus day 1 ). We suspect that the main reason for the different results is the use of an extended access nicotine self-administration procedure $(23 \mathrm{~h} / \mathrm{d})$ in the Abdolahi et al. (2010) study versus a limited access selfadministration procedure $(2 \mathrm{~h} / \mathrm{d})$ used in our study.

Finally, under our experimental conditions, incubation of nicotine craving was not observed after 1 month of withdrawal. In contrast, reliable incubation of heroin (Airavaara et al., 2011), 
A Timeline: Experiment 3

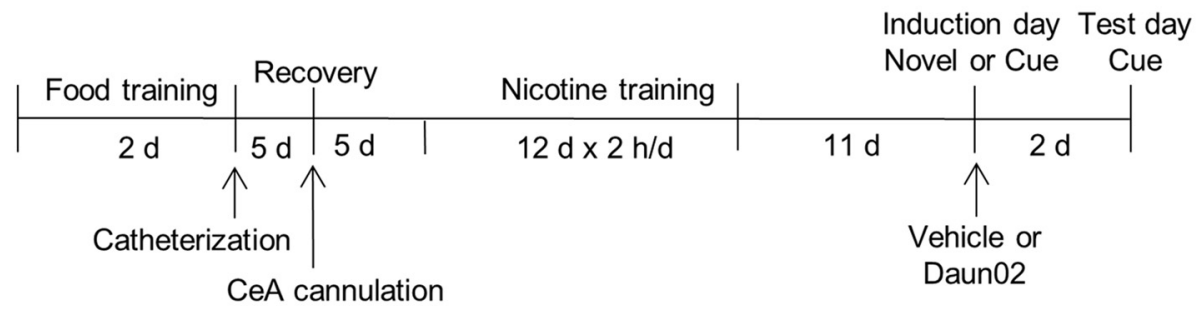

B Nicotine self-administration
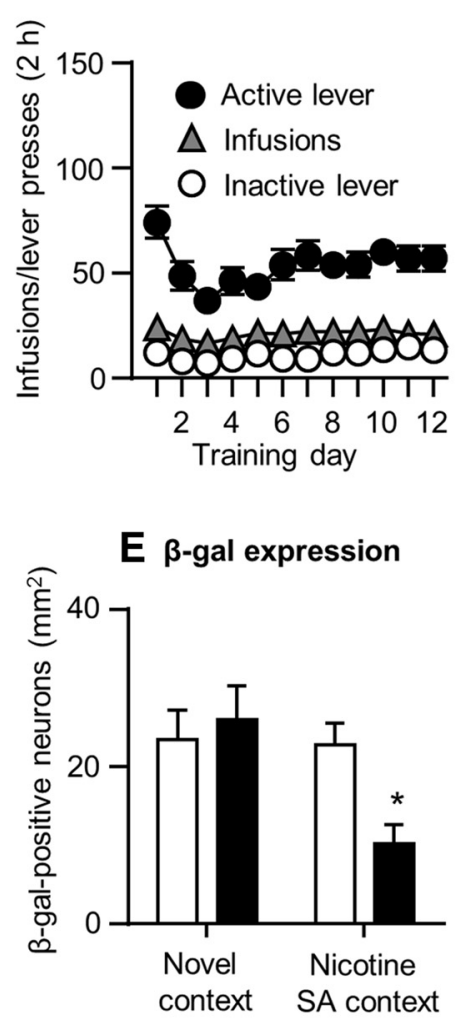

C Extinction test

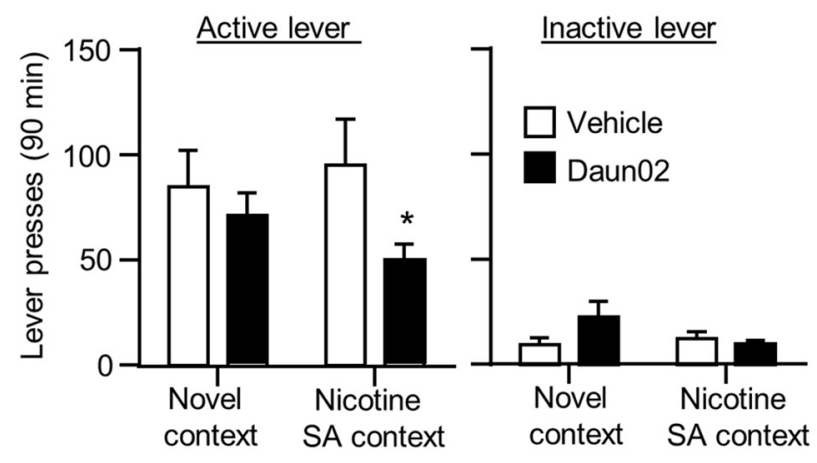

D Cannula placements

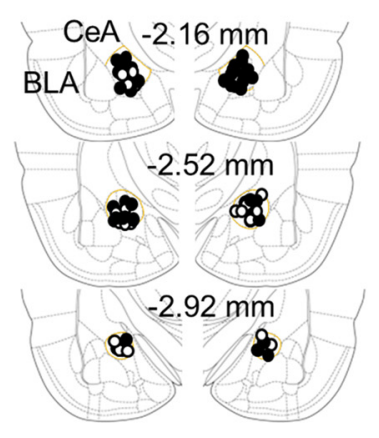

Figure 5. Daun02 injections into the CeA of adult Fos-lacZ rats decreased incubated nicotine seeking on withdrawal day 14 . $\boldsymbol{A}$, Timeline of the experimental procedure. $\boldsymbol{B}$, Nicotine selfadministration. Data are mean \pm SEM of nicotine infusions and active and inactive lever presses of all rats (total $n=42$ ) during the 12 training days. $C$, Extinction responding. Data are mean \pm SEM of presses on the previously active lever and on the inactive lever during the extinction test after 14 withdrawal days. $\boldsymbol{D}$, Cannula placements. Numbers indicate $\mathrm{mm}$ from bregma. $\boldsymbol{E}, \beta$-gal expression. Left, Mean \pm SEM $\beta$-gal-positive neurons in the CeA in the four groups. Right, Representative photomicrographs of $\beta$-gal expression in the CeA of rats in the different treatment groups. We injected the rats with Daun02 or vehicle 75 min after a short 15 min extinction session or exposure to a novel context on withdrawal day $11 . n=9-12$ per group.

methamphetamine (Li et al., 2015b), and cocaine (Lu et al., 2009) craving are observed at this withdrawal time period, as well as after longer withdrawal periods (Lu et al., 2004a; Venniro et al., 2016; Wolf, 2016). These time course differences may reflect drug-specific differences in the duration of incubation of craving (Pickens et al., 2011), but may also reflect the use of a limitedaccess training procedure in our study.

Brain circuits of incubation of nicotine craving

Previous studies implicated the CeA in incubation of cocaine ( $\mathrm{Lu}$ et al., 2005; Lu et al., 2007; Xi et al., 2013) and methamphetamine (Li et al., 2015b) craving and the OFC in incubation of heroin craving (Fanous et al., 2012). There is also evidence for a role of the NAc core and shell in incubation of cocaine and methamphetamine craving (Conrad et al., 2008; Koya et al., 2009b; Xi et al., 2013; Scheyer et al., 2016), as well as projections from BLA to NAc shell and dorsal mPFC to NAc core in incubation of cocaine craving (Lee et al., 2013; Ma et al., 2014). Here, we found that, in both age groups, incubation of nicotine craving was associated with time-dependent increases in Fos expression in these brain regions. These results suggest a role of Fos-positive activated neurons in these regions in incubation of nicotine craving. However, Fos data are correlational, so it is unknown whether increased Fos expression is a cause or a consequence of drug seeking (Bossert et al., 2011). Therefore, in Experiments 2-3, we used the Daun02 inactivation method (Cruz et al., 2013) to determine the causal role of $\mathrm{CeA}$ and $\mathrm{OFC}$ neurons activated during incubated nicotine seeking. Koya et al. (2009b) developed this method to determine the causal role of activated neuronal ensembles in conditioned drug effects, drug relapse, and learned behaviors.

Daun02 inactivation of the CeA, but not OFC, decreased incubated nicotine seeking on withdrawal day 14, suggesting a causal role of CeA neuronal ensembles in incubation of nicotine craving. Importantly, CeA Daun02 injections after exposure to a 
novel context, which induces strong Fos expression (Badiani et al., 1998, 1999; Badiani and Robinson, 2004), had no effect on incubated nicotine seeking. These data indicate that Daun02's effect on nicotine seeking is not due to nonselective effects on CeA function. Our data on the role of CeA in incubation of nicotine craving are in agreement with previous data on the role of this region in incubation of cocaine, morphine, and methamphetamine craving (Lu et al., 2005; Lu et al., 2007; Li et al., 2008; Li et al., 2015a). Our data are also in agreement with previous human imaging studies showing that exposure to nicotineassociated cues increases BOLD activity in the amygdala (McClernon et al., 2007; Wang et al., 2007; Sutherland et al., 2013). More generally, the previous and present results on the CeA's role in incubation of drug craving are in agreement with the notion that this brain area plays a critical role in the incentive motivational effects of reward-associated cues and reward seeking (Cardinal et al., 2002; Mahler and Berridge, 2012; Richard et al., 2013; Robinson et al., 2014).

The cellular mechanisms that underlie the effect of incubated nicotine seeking on CeA neuronal activity are unknown. Based on previous studies, we speculate that this activity is mediated by the extracellular signal-regulated kinase (ERK) signaling pathway (Lu et al., 2005; Li et al., 2008), the activation of which in different brain areas leads to Fos induction after exposure to drug and nondrug stimuli (Valjent et al., 2000; Mattson et al., 2005; Lu et al., 2006; Girault et al., 2007).

Finally, unlike our CeA results, Daun02 inactivation of activated Fos-positive OFC neurons had no effect on incubation of nicotine craving. These results are different from our previous results on the effect of Daun02 inactivation of OFC neuronal ensembles on incubation of heroin craving (Fanous et al., 2012). These different results are in agreement with the notion that the circuits controlling incubation of drug craving and relapse across drug classes are not identical (Badiani et al., 2011; Bossert et al., 2013; Marchant et al., 2013).

\section{Conclusions}

We characterized the time course of incubation of nicotine craving after adolescent-onset and adult-onset nicotine self-administration. We found that, in both age groups, maximal incubated drug seeking was observed after 14 withdrawal days and the incubated response was associated with increased neuronal activity in $\mathrm{mPFC}$, OFC, nucleus accumbens, and amygdala. More importantly, we used the Daun02 inactivation procedure to demonstrate a causal role of CeA neuronal ensembles in incubation of nicotine craving. These results, together with previous results with cocaine, morphine, and methamphetamine, establish that CeA neuronal activity is critical for incubation of drug craving across drug classes. Based on our Fos results, a question for future research is whether neuronal ensembles in mPFC, NAc, and BLA also play a causal role in the incubation of nicotine craving.

\section{References}

Abdolahi A, Acosta G, Breslin FJ, Hemby SE, Lynch WJ (2010) Incubation of nicotine seeking is associated with enhanced protein kinase A-regulated signaling of dopamine- and cAMP-regulated phosphoprotein of $32 \mathrm{kDa}$ in the insular cortex. Eur J Neurosci 31:733-741. CrossRef Medline

Adriani W, Spijker S, Deroche-Gamonet V, Laviola G, Le Moal M, Smit AB, Piazza PV (2003) Evidence for enhanced neurobehavioral vulnerability to nicotine during periadolescence in rats. J Neurosci 23:4712-4716. Medline

Airavaara M, Pickens CL, Stern AL, Wihbey KA, Harvey BK, Bossert JM, Liu QR, Hoffer BJ, Shaham Y (2011) Endogenous GDNF in ventral tegmen- tal area and nucleus accumbens does not play a role in the incubation of heroin craving. Addict Biol 16:261-272. CrossRef Medline

Badiani A, Robinson TE (2004) Drug-induced neurobehavioral plasticity: the role of environmental context. Behav Pharmacol 15:327-339. CrossRef Medline

Badiani A, Oates MM, Day HE, Watson SJ, Akil H, Robinson TE (1998) Amphetamine-induced behavior, dopamine release, and c-fos mRNA expression: modulation by environmental novelty. J Neurosci 18:1057910593. Medline

Badiani A, Oates MM, Day HE, Watson SJ, Akil H, Robinson TE (1999) Environmental modulation of amphetamine-induced c-fos expression in D1 versus D2 striatal neurons. Behav Brain Res 103:203-209. CrossRef Medline

Badiani A, Belin D, Epstein D, Calu D, Shaham Y (2011) Opiate versus psychostimulant addiction: the differences do matter. Nat Rev Neurosci 12:685-700. CrossRef Medline

Bedi G, Preston KL, Epstein DH, Heishman SJ, Marrone GF, Shaham Y, de Wit H (2011) Incubation of cue-induced cigarette craving during abstinence in human smokers. Biol Psychiatry 69:708-711. CrossRef Medline

Belluzzi JD, Wang R, Leslie FM (2005) Acetaldehyde enhances acquisition of nicotine self-administration in adolescent rats. Neuropsychopharmacology 30:705-712. CrossRef Medline

Ben-Shahar O, Sacramento AD, Miller BW, Webb SM, Wroten MG, Silva HE, Caruana AL, Gordon EJ, Ploense KL, Ditzhazy J, Kippin TE, Szumlinski KK (2013) Deficits in ventromedial prefrontal cortex group 1 metabotropic glutamate receptor function mediate resistance to extinction during protracted withdrawal from an extensive history of cocaine selfadministration. J Neurosci 33:495-506a. CrossRef Medline

Bienkowski P, Rogowski A, Korkosz A, Mierzejewski P, Radwanska K, Kaczmarek L, Bogucka-Bonikowska A, Kostowski W (2004) Timedependent changes in alcohol-seeking behaviour during abstinence. Eur Neuropsychopharmacol 14:355-360. CrossRef Medline

Bossert JM, Stern AL, Theberge FR, Cifani C, Koya E, Hope BT, Shaham Y (2011) Ventral medial prefrontal cortex neuronal ensembles mediate context-induced relapse to heroin. Nat Neurosci 14:420-422. CrossRef Medline

Bossert JM, Marchant NJ, Calu DJ, Shaham Y (2013) The reinstatement model of drug relapse: recent neurobiological findings, emerging research topics, and translational research. Psychopharmacology 229:453-476. CrossRef Medline

Brady JV (1991) Animal models for assessing drugs of abuse. Neurosci Biobehav Rev 15:35-43. CrossRef Medline

Cardinal RN, Parkinson JA, Hall J, Everitt BJ (2002) Emotion and motivation: the role of the amygdala, ventral striatum, and prefrontal cortex. Neurosci Biobehav Rev 26:321-352. CrossRef Medline

Clark DB, Kirisci L, Moss HB (1998) Early adolescent gateway drug use in sons of fathers with substance use disorders. Addict Behav 23:561-566. CrossRef Medline

Conrad KL, Tseng KY, Uejima JL, Reimers JM, Heng LJ, Shaham Y, Marinelli M, Wolf ME (2008) Formation of accumbens GluR2-lacking AMPA receptors mediates incubation of cocaine craving. Nature 454:118-121. CrossRef Medline

Counotte DS, Schiefer C, Shaham Y, O'Donnell P (2014) Time-dependent decreases in nucleus accumbens AMPA/NMDA ratio and incubation of sucrose craving in adolescent and adult rats. Psychopharmacology 231: 1675-1684. CrossRef Medline

Cruz FC, Koya E, Guez-Barber DH, Bossert JM, Lupica CR, Shaham Y, Hope BT (2013) New technologies for examining the role of neuronal ensembles in drug addiction and fear. Nat Rev Neurosci 14:743-754. CrossRef Medline

Cruz FC, Babin KR, Leao RM, Goldart EM, Bossert JM, Shaham Y, Hope BT (2014) Role of nucleus accumbens shell neuronal ensembles in contextinduced reinstatement of cocaine-seeking. J Neurosci 34:7437-7446. CrossRef Medline

Doherty JM, Frantz KJ (2012) Heroin self-administration and reinstatement of heroin-seeking in adolescent vs. adult male rats. Psychopharmacology 219:763-773. CrossRef Medline

Doherty JM, Cooke BM, Frantz KJ (2013) A role for the prefrontal cortex in heroin-seeking after forced abstinence by adult male rats but not adolescents. Neuropsychopharmacology 38:446-454. CrossRef Medline

Eissenberg T, Balster RL (2000) Initial tobacco use episodes in children and adolescents: current knowledge, future directions. Drug Alcohol Depend 59:S41-S60. Medline 
Epstein DH, Preston KL, Stewart J, Shaham Y (2006) Toward a model of drug relapse: an assessment of the validity of the reinstatement procedure. Psychopharmacology 189:1-16. CrossRef Medline

Fanous S, Goldart EM, Theberge FR, Bossert JM, Shaham Y, Hope BT (2012) Role of orbitofrontal cortex neuronal ensembles in the expression of incubation of heroin craving. J Neurosci 32:11600-11609. CrossRef Medline

Girault JA, Valjent E, Caboche J, Hervé D (2007) ERK2: a logical AND gate critical for drug-induced plasticity? Curr Opin Pharmacol 7:77-85. CrossRef Medline

Grimm JW, Hope BT, Wise RA, Shaham Y (2001) Neuroadaptation: incubation of cocaine craving after withdrawal. Nature 412:141-142. CrossRef Medline

Heilig M, Epstein DE, Nader M, Shaham Y (2016) It is time to connect: Addiction neuroscience and social context. Nat Rev Neurosci, in press.

Johnson D (2001) Age of illicit drug initiation. Trends Issues Crime Crim Justice 201:1-6.

Kasof GM, Smeyne RJ, Curran T, Morgan JI (1996) Developmental expression of Fos-lacZ in the brains of postnatal transgenic rats. Brain Res Dev Brain Res 93:191-197. CrossRef Medline

Kenny PJ, Markou A (2006) Nicotine self-administration acutely activates brain reward systems and induces a long-lasting increase in reward sensitivity. Neuropsychopharmacology 31:1203-1211. Medline

Khuder SA, Dayal HH, Mutgi AB (1999) Age at smoking onset and its effect on smoking cessation. Addict Behav 24:673-677. CrossRef Medline

Koya E, Uejima JL, Wihbey KA, Bossert JM, Hope BT, Shaham Y (2009a) Role of ventral medial prefrontal cortex in incubation of cocaine craving. Neuropharmacology 56:177-185. CrossRef Medline

Koya E, Golden SA, Harvey BK, Guez-Barber DH, Berkow A, Simmons DE, Bossert JM, Nair SG, Uejima JL, Marin MT, Mitchell TB, Farquhar D, Ghosh SC, Mattson BJ, Hope BT (2009b) Targeted disruption of cocaine-activated nucleus accumbens neurons prevents context-specific sensitization. Nat Neurosci 12:1069-1073. CrossRef Medline

Lê AD, Li Z, Funk D, Shram M, Li TK, Shaham Y (2006) Increased vulnerability to nicotine self-administration and relapse in alcohol-naive offspring of rats selectively bred for high alcohol intake. J Neurosci 26: 1872-1879. CrossRef Medline

Lee BR, Ma YY, Huang YH, Wang X, Otaka M, Ishikawa M, Neumann PA, Graziane NM, Brown TE, Suska A, Guo C, Lobo MK, Sesack SR, Wolf ME, Nestler EJ, Shaham Y, Schlüter OM, Dong Y (2013) Maturation of silent synapses in amygdala-accumbens projection contributes to incubation of cocaine craving. Nat Neurosci 16:1644-1651. CrossRef Medline

Levin ED, Rezvani AH, Montoya D, Rose JE, Swartzwelder HS (2003) Adolescent-onset nicotine self-administration modeled in female rats. Psychopharmacology 169:141-149. CrossRef Medline

Li C, Frantz KJ (2009) Attenuated incubation of cocaine seeking in male rats trained to self-administer cocaine during periadolescence. Psychopharmacology 204:725-733. CrossRef Medline

Li X, Zeric T, Kambhampati S, Bossert JM, Shaham Y (2015a) The central amygdala nucleus is critical for incubation of methamphetamine craving. Neuropsychopharmacology 40:1297-1306. CrossRef Medline

Li X, Rubio FJ, Zeric T, Bossert JM, Kambhampati S, Cates HM, Kennedy PJ, Liu QR, Cimbro R, Hope BT, Nestler EJ, Shaham Y (2015b) Incubation of methamphetamine craving is associated with selective increases in expression of Bdnf and trkb, glutamate receptors, and epigenetic enzymes in cue-activated fos-expressing dorsal striatal neurons. J Neurosci 35: 8232-8244. CrossRef Medline

Li YQ, Li FQ, Wang XY, Wu P, Zhao M, Xu CM, Shaham Y, Lu L (2008) Central amygdala extracellular signal-regulated kinase signaling pathway is critical to incubation of opiate craving. J Neurosci 28:13248-13257. CrossRef Medline

Loweth JA, Scheyer AF, Milovanovic M, LaCrosse AL, Flores-Barrera E, Werner CT, Li X, Ford KA, Le T, Olive MF, Szumlinski KK, Tseng KY, Wolf ME (2014) Synaptic depression via mGluR1 positive allosteric modulation suppresses cue-induced cocaine craving. Nat Neurosci 17:73-80. Medline

Lu L, Grimm JW, Hope BT, Shaham Y (2004a) Incubation of cocaine craving after withdrawal: a review of preclinical data. Neuropharmacology 47:214-226. CrossRef Medline

Lu L, Grimm JW, Dempsey J, Shaham Y (2004b) Cocaine seeking over extended withdrawal periods in rats: different time courses of responding induced by cocaine cues versus cocaine priming over the first 6 months. Psychopharmacology 176:101-108. CrossRef Medline
Lu L, Hope BT, Dempsey J, Liu SY, Bossert JM, Shaham Y (2005) Central amygdala ERK signaling pathway is critical to incubation of cocaine craving. Nat Neurosci 8:212-219. CrossRef Medline

Lu L, Koya E, Zhai H, Hope BT, Shaham Y (2006) Role of ERK in cocaine addiction. Trends Neurosci 29:695-703. CrossRef Medline

Lu L, Uejima JL, Gray SM, Bossert JM, Shaham Y (2007) Systemic and central amygdala injections of the mGluR(2/3) agonist LY379268 attenuate the expression of incubation of cocaine craving. Biol Psychiatry 61: 591-598. CrossRef Medline

Lu L, Wang X, Wu P, Xu C, Zhao M, Morales M, Harvey BK, Hoffer BJ, Shaham Y (2009) Role of ventral tegmental area glial cell line-derived neurotrophic factor in incubation of cocaine craving. Biol Psychiatry 66: 137-145. CrossRef Medline

Ma YY, Lee BR, Wang X, Guo C, Liu L, Cui R, Lan Y, Balcita-Pedicino JJ, Wolf ME, Sesack SR, Shaham Y, Schlüter OM, Huang YH, Dong Y (2014) Bidirectional modulation of incubation of cocaine craving by silent synapse-based remodeling of prefrontal cortex to accumbens projections. Neuron 83:1453-1467. CrossRef Medline

Mahler SV, Berridge KC (2012) What and when to "want"? Amygdalabased focusing of incentive salience upon sugar and sex. Psychopharmacology 221:407-426. CrossRef Medline

Marchant NJ, Li X, Shaham Y (2013) Recent developments in animal models of drug relapse. Curr Opin Neurobiol 23:675-683. CrossRef Medline

Mattson BJ, Bossert JM, Simmons DE, Nozaki N, Nagarkar D, Kreuter JD, Hope BT (2005) Cocaine-induced CREB phosphorylation in nucleus accumbens of cocaine-sensitized rats is enabled by enhanced activation of extracellular signal-related kinase, but not protein kinase A. J Neurochem 95:1481-1494. CrossRef Medline

McClernon FJ, Hiott FB, Liu J, Salley AN, Behm FM, Rose JE (2007) Selectively reduced responses to smoking cues in amygdala following extinction-based smoking cessation: results of a preliminary functional magnetic resonance imaging study. Addict Biol 12:503-512. CrossRef Medline

McCutcheon JE, Marinelli M (2009) Age matters. Eur J Neurosci 29: 997-1014. CrossRef Medline

Morgan JI, Curran T (1991) Stimulus-transcription coupling in the nervous system: involvement of the inducible proto-oncogenes fos and jun. Annu Rev Neurosci 14:421-451. CrossRef Medline

Neisewander JL, Baker DA, Fuchs RA, Tran-Nguyen LT, Palmer A, Marshall JF (2000) Fos protein expression and cocaine-seeking behavior in rats after exposure to a cocaine self-administration environment. J Neurosci 20:798-805. Medline

Paxinos G, Watson C (2005) The rat brain in stereotaxic coordinates, Ed. Amsterdam: Elsevier.

Pfarr S, Meinhardt MW, Klee ML, Hansson AC, Vengeliene V, Schönig K, Bartsch D, Hope BT, Spanagel R, Sommer WH (2015) Losing control: excessive alcohol seeking after selective inactivation of cue-responsive neurons in the infralimbic cortex. J Neurosci 35:10750-10761. CrossRef Medline

Pickens CL, Airavaara M, Theberge F, Fanous S, Hope BT, Shaham Y (2011) Neurobiology of the incubation of drug craving. Trends Neurosci 34: 411-420. CrossRef Medline

Richard JM, Castro DC, Difeliceantonio AG, Robinson MJ, Berridge KC (2013) Mapping brain circuits of reward and motivation: in the footsteps of Ann Kelley. Neurosci Biobehav Rev 37:1919-1931. CrossRef Medline

Robinson MJ, Warlow SM, Berridge KC (2014) Optogenetic excitation of central amygdala amplifies and narrows incentive motivation to pursue one reward above another. J Neurosci 34:16567-16580. CrossRef Medline

Rose JE, Corrigall WA (1997) Nicotine self-administration in animals and humans: similarities and differences. Psychopharmacology 130:28-40. CrossRef Medline

Scheyer AF, Loweth JA, Christian DT, Uejima J, Rabei R, Le T, Dolubizno H, Stefanik MT, Murray CH, Sakas C, Wolf ME (2016) AMPA receptor plasticity in accumbens core contributes to incubation of methamphetamine craving. Biol Psychiatry, in press.

Shaham Y, Adamson LK, Grocki S, Corrigall WA (1997) Reinstatement and spontaneous recovery of nicotine-seeking in rats. Psychopharmacology 130:396-403. CrossRef Medline

Shalev U, Morales M, Hope B, Yap J, Shaham Y (2001) Time-dependent changes in extinction behavior and stress-induced reinstatement of drug seeking following withdrawal from heroin in rats. Psychopharmacology 156:98-107. CrossRef Medline 
Shepard JD, Bossert JM, Liu SY, Shaham Y (2004) The anxiogenic drug yohimbine reinstates methamphetamine seeking in a rat model of drug relapse. Biol Psychiatry 55:1082-1089. CrossRef Medline

Shoaib M, Schindler CW, Goldberg SR (1997) Nicotine self-administration in rats: strain and nicotine pre-exposure effects on acquisition. Psychopharmacology 129:35-43. CrossRef Medline

Shram MJ, Li Z, Lê AD (2008a) Age differences in the spontaneous acquisition of nicotine self-administration in male Wistar and Long-Evans rats. Psychopharmacology 197:45-58. CrossRef Medline

Shram MJ, Funk D, Li Z, Lê AD (2008b) Nicotine self-administration, extinction responding and reinstatement in adolescent and adult male rats: evidence against a biological vulnerability to nicotine addiction during adolescence. Neuropsychopharmacology 33:739-748. CrossRef Medline

Spear LP (2000) The adolescent brain and age-related behavioral manifestations. Neurosci Biobehav Rev 24:417-463. CrossRef Medline

Sutherland MT, Carroll AJ, Salmeron BJ, Ross TJ, Hong LE, Stein EA (2013) Down-regulation of amygdala and insula functional circuits by vareni- cline and nicotine in abstinent cigarette smokers. Biol Psychiatry 74: 538-546. CrossRef Medline

Valjent E, Corvol JC, Pages C, Besson MJ, Maldonado R, Caboche J (2000) Involvement of the extracellular signal-regulated kinase cascade for cocaine-rewarding properties. J Neurosci 20:8701-8709. Medline

Venniro M, Caprioli D, Shaham Y (2016) Animal models of drug relapse and craving: From drug priming-induced reinstatement to incubation of craving after voluntary abstinence. Prog Brain Res 224:25-52. CrossRef Medline

Wang Z, Faith M, Patterson F, Tang K, Kerrin K, Wileyto EP, Detre JA, Lerman C (2007) Neural substrates of abstinence-induced cigarette cravings in chronic smokers. J Neurosci 27:14035-14040. CrossRef Medline

Wolf ME (2016) Synaptic mechanisms underlying persistent cocaine craving. Nat Rev Neurosci 17:351-365. CrossRef Medline

Xi ZX, Li X, Li J, Peng XQ, Song R, Gaál J, Gardner EL (2013) Blockade of dopamine $\mathrm{D} 3$ receptors in the nucleus accumbens and central amygdala inhibits incubation of cocaine craving in rats. Addict Biol 18:665-677. CrossRef Medline 